\title{
Níveis de Energia em Dietas para Ovinos Santa Inês: Características de Carcaça e Cons- tituintes Corporais ${ }^{1}$
}

\section{Kaliandra Souza Alves ${ }^{2}$, Francisco Fernando Ramos de Carvalho ${ }^{3}$, Marcelo de Andrade Ferreira $^{3}$, Antônia Sherlânea Chaves Véras ${ }^{3}$, Ariosvaldo Nunes de Medeiros ${ }^{4}$, Jansen Ferreira do Nascimento ${ }^{5}$, Luciana Remígio Santos Nascimento ${ }^{5}$, Amanda Valéria Aureliano dos Anjos ${ }^{5}$}

RESUMO - As características de carcaça, o rendimento dos cortes e os constituintes corporais foram determinados em função dos diferentes níveis de energia na dieta. Utilizaram-se 18 ovinos da raça Santa Inês, machos não-castrados, com idade média de seis meses e peso vivo médio de $20 \mathrm{~kg}$, alimentados com dietas que continham 2,42;2,66; e 2,83 Mcal de energia metabolizável (EM)/kg de matéria seca (MS). O peso de abate estabelecido foi de $33 \mathrm{~kg}$ de peso vivo (PV). Os animais foram distribuídos em delineamento em blocos casualizados, com três tratamentos e seis repetições. Houve efeito linear decrescente para perda de peso no jejum (PJ) e linear crescente para pesos das carcaças quente (PCQ) e fria (PCF), rendimentos de carcaças quente (RCQ) e fria (RCF) e peso do corpo vazio (PCV). No entanto, a perda no resfriamento (PR) e o rendimento verdadeiro (RV) não foram influenciados pelos níveis de energia na dieta. Para os cortes e seus respectivos rendimentos, em relação ao peso da carcaça fria (PCF), não houve efeito para nenhuma das variáveis analisadas, exceto para os pesos de paleta e costela superior, que mostraram efeito linear crescente com o aumento nos níveis de energia na dieta. Os índices de compacidade de carcaça e perna não foram influenciados pelo incremento energético na dieta. Quanto à espessura de gordura e área de olho de lombo, não foram encontrados efeitos significativos. Não foi observado efeito significativo para os constituintes não-carcaça, exceto para gordura interna-GI e para conteúdo do trato gastrintestinal - CTGI e rúmen/retículo - R/R, que mostraram efeito linear crescente e decrescente, respectivamente.

Palavras-chave: cortes, rendimento, órgãos

\section{Dietary Energy Levels for Santa Inês Sheep: Carcass Characteristics and Body Constituents}

ABSTRACT - Carcass characteristics, cut dressing and body constituents were determined according to the different dietary energy levels. Eighteen Santa Inês sheep (averaging live weight of $20 \mathrm{~kg}$ and six months old) were full fed diets with 2.43, 2.66 and 2.88 Mcal of metabolizable energy (ME)/kg of dry matter (DM). The animals were slaughtered when reached $33 \mathrm{~kg}$ live weight (LW). A randomized block design, with six replicates, was used. Linear decreasing effect was observed for loss in fast (LF) and linear increase for hot (HCW) and cold (CCW) carcass weight, hot (HCD) and cold (CCD) carcass dressing and empty body weight (EBW). However, the loss in cooling (LC) and true dressing (TD) were not affected by the dietary energy levels. For the cuts and its respective dressing in relation to the $\mathrm{CCW}$, no effect was observed for the analyzed variables, except for shoulder weight and superior rib weight, that showed increasing linear effect, as the dietary energy levels increased. The compactness index of the carcass and leg showed no effect, as the dietary energy levels increased. Fat thichness and loin eye area showed no significant effects. No significant effect was observed for the noncarcass constituents, except for the internal fat (IF) and for the content of gastrointestinal tract - CGT and rumen/reticulum - R/R, that showed linear increasing effect and linear decreasing effect, respectively.

Key Words: cuts, dressing, organs

\section{Introdução}

Na região nordeste do Brasil, a ovinocultura possui grande importância sócio-econômica e está voltada principalmente para a produção de carne. Todavia, o desfrute do rebanho ovino é, em sua maioria, baixo, em conseqüência das altas taxas de mortalidade pré e pós-desmame e da avançada idade de abate. Esse baixo desfrute é creditado às deficiências sanitárias e principalmente nutricionais.

A carne ovina no Brasil possui baixo consumo, principalmente devido à má qualidade do produto comercializado (Garcia et al., 2000). O confinamento é uma das tecnologias que pode ser empregada para

\footnotetext{
${ }^{1}$ Parte da dissertação apresentada pelo primeiro autor à Universidade Federal Rural de Pernambuco.

2Doutoranda em Zootecnia. Bolsista do CNPq. E.mail: kally_alves@hotmail.com

3 Professor do DZ/UFRPE. E.mail: ffrcarva@ufrpe.br; ferreira@ufrpe.br; sherlanea@ig.com.br

4 Professor do DAP/CCA/UFPB. E.mail: medeiros@cca.ufpb

${ }^{5}$ Aluno de graduação Zootecnia - UFRPE.
} 
o aumento dos índices de produtividade da ovinocultura emelhoria da qualidade do produto (Carvalho \& Siqueira, 2001). Através do fornecimento de rações balanceadas é possível conseguir maior ganho diário em peso e redução da idade ao abate, com reflexos positivos sobre a qualidade das carcaças e sobre a oferta de carne na entressafra (Oliveira et al., 1998 a, b).

No sistema de produção de carne, as características quantitativas e qualitativas da carcaça são de fundamental importância, pois estão diretamente relacionadas ao produto final. No entanto, para a melhoria da produção e da produtividade, o conhecimento do potencial do animal em produzir carne é fundamental, e, entre as formas para avaliar essa capacidade, está o rendimento de carcaça. No estudo de carcaças ovinas, o rendimento é, geralmente, o primeiroíndice a ser considerado, expressando a relação percentual entre os pesos da carcaça e do animal.

Uma das peculiaridades da espécie ovina é apresentar alta eficiência para ganho em peso e qualidade de carne. Porém, a produção e comercialização de carne de ovinos no Brasil ainda encontram-se desorganizadas. Apresenta baixa oferta e a maioria dos produtores não está conscientizada da necessidade de se produzir carne de boa qualidade, levando ao mercado animais com idade avançada, que vêm contribuir para dificultar ainda mais o aumento do consumo. Dessa forma, a prática de confinamento permite disponibilizar ao mercado consumidor um animal mais jovem com características de carcaça desejáveis, o que pode contribuir com a expansão do consumo.

De acordo com Osório et al. (1992), como conseqüência dos distintos sistemas de produção e das raças, o mercado de carne ovina apresenta grande variabilidade dos caracteres qualitativos e quantitativos que definem os diferentes tipos de carcaças comercializadas. Porém, Silva \& Pires (2000) relataram que esta variabilidade não constitui inconveniente para a comercialização, por oferecer ao mercado carcaças diferentes, que podem satisfazer às mais variadas preferências da demanda.

Existem fatores determinantes das características relacionadas à qualidade e quantidade da carcaça e da carne, tais como raça, sexo, idade e principalmente aqueles relativos ao meio e à nutrição (Osório, 1998; Osório \& Osório, 2001). Dentre esses fatores, vários podem afetar o rendimento de carcaça, sobretudo a alimentação, que, inquestionavelmente, é um dos mais preponderantes, especialmente os níveis de energia na dieta.
Existem poucos trabalhos de pesquisa no Brasil destinados ao conhecimento dos níveis ideais dos nutrientes exigidos pela espécie e seus possíveis efeitos sobre as características de carcaça. Dentre os nutrientes a serem supridos, a energia tem recebido atenção especial por ser de fundamental importância para o funcionamento dos órgãos vitais, a atividade e renovação das células e processos de utilização dos nutrientes, entre outros (Zundt et al., 2001). De acordo com Mahgoub et al. (2000), a suplementação de energia melhora a eficiência de crescimento.

Zundt et al. (2001), avaliando características de carcaça de caprinos com 60 dias de idade e $17 \mathrm{~kg}$ de peso vivo (PV), alimentados com diferentes níveis de energia metabolizável (EM), 1,76; 1,96; 2,15 e 2,35 Mcal/kg de matéria seca (MS), encontraram efeito linear crescente para pesos da carcaça quente (PCQ) e fria (PCF) e rendimentos de carcaças quente (RCQ) e fria (RCF).

Mahgoub et al. (2000), trabalhando com baixo, médio e alto (2,39; 2,47 e 2,74 Mcal EM/kg de MS) níveis de energia na dieta de ovinos, encontraram diferenças significativas para peso do corpo vazio (PCV), PCQ e PCF. Também, Martins et al. (1999), trabalhando com 2,17 e 2,72 Mcal de EM/kg de MS em dietas de cordeiros mestiços Texel, terminados em confinamento, encontraram maiores valores para os rendimentos comercial e biológico das carcaças para o nível mais elevado de energia.

Garcia et al. (2001a), avaliando as características de carcaça de ovinos Santa Inês, recebendo rações com $80 \%$ de concentrado, e 2,8 Mcal EM/kg de MS, encontraram valores de $17,33 \mathrm{~kg}, 49,66 \%$ e $47,56 \%$, para peso da carcaça fria, rendimento verdadeiro da carcaça e rendimento comercial da carcaça, respectivamente.

As carcaças podem ser comercializadas inteiras ou sob forma de cortes. Os cortes cárneos em peças individualizadas associados à apresentação do produto são importantes fatores na comercialização. $\mathrm{O}$ tipo de corte varia de região para região e principalmente entre países. Todavia, os sistemas de cortes, além de proporcionarem obtenção de preços diferenciados entre diversas partes da carcaça, permitem aproveitamento racional, evitando-se desperdícios (Silva Sobrinho \& Silva, 2000), e a proporção desses cortes constitui um importante índice para avaliação da sua qualidade.

Garcia et al. (1999), trabalhando com dietas contendo 2,6 Mcal de EM/kg de MS para cordeiros 
Mestiços Ideal x Ile de France, abatidos aos $34 \mathrm{~kg}$ de peso vivo (PV), observaram rendimentos em porcentagem do peso da carcaça de 33,27; 20,24; 9,88; 9,69; e $8,70 \%$ para perna, paleta, lombo, baixo e pescoço, respectivamente.

Avaliando dietas com 2,8 Mcal de EM/kg de MS, compostas por $80 \%$ de concentrado, para ovinos Santa Inês abatidos aos $35 \mathrm{Kg}$ de peso vivo ao abate (PVA), Garcia et al. (2001b) encontraram rendimentos de 7,25;3,54; e 13,36\% para paleta, lombo e pernil, respectivamente. Com valor semelhante de energia (2,7 Mcal de EM/kg de MS), Pérez et al. (1998a) encontraram 2,01; 0,98; e 3,52 kg, para rendimento de paleta, lombo e pernil, respectivamente.

A comercialização do animal como um todo deve levar em consideração não somente o peso vivo, mas a proporção de seus componentes, ou seja, carcaça e não-carcaça e a valorização desses. O estudo dos constituintes menos nobres do corpo do animal, como fígado, baço, coração, rins e outros são informações que podem vir auxiliar na determinação da quantificação dos órgãos que possuem importância econômica, uma vez que pode agregar valores à produção ovina. Os órgãos e víceras possuem distintas velocidades de crescimento durante a vida do animal comparados com outras partes do corpo (Kamalzadeh et al., 1998), e podem ser influenciados pela composição química da dieta, especialmente a energia.

Pérez et al. (1998b) utilizaram 2,7 Mcal de EM/kg de MS e encontraram valores de 0,$46 ; 0,20 ; 0,90$; 0,$10 ; 0.97 ; 0,10 ; 0,16 ; 0,67 ;$ e $0,43 \mathrm{~kg}$ para peso de pulmão, coração, fígado, baço, rúmen/retículo, omaso, abomaso, intestino delgado e intestino grosso, respectivamente. Já McLeod \& Baldwin (2000) trabalharam com 2,29 e 2,81 Mcal de EM/kg de MS em dietas de cordeiros e encontraram maiores pesos para rúmen/retículo, omaso, abomaso, intestino delgado, intestino grosso, fígado, coração, pulmões e rins, no nível mais alto de energia metabolizável.

O objetivo desse trabalho foi avaliar as características de carcaça, rendimentos dos cortes e constituintes corporais de ovinos Santa Inês alimentados com dietas contendo diferentes níveis de energia.

\section{Material e Métodos}

Este trabalho foi conduzido em 2001, no Galpão de Desempenho e Digestibilidade do Setor de Caprinoovinocultura do Departamento de Zootecnia da Universidade Federal Rural de Pernambuco - UFRPE, localizada em Recife-PE, situada na micro-região fisiográfica do Litoral Mata, pertencente à Região Metropolitana do Recife - RMR.

Foram utilizados 18 ovinos Santa Inês, machos não-castrados, em crescimento, com idade média de seis meses e peso vivo médio de $20 \mathrm{~kg}$. Os animais foram alojados, individualmente, em baias, medindo $1,1 \mathrm{~m} \times 0,55 \mathrm{~m}$, providas de comedouros e bebedouros, onde receberam os tratamentos experimentais, constituídos por feno de capim-Tifton-85 (Cynodon dactylon), moído em máquina forrageira com peneira de crivo de $8 \mathrm{~mm}$ e diferentes níveis de concentrado, à base de milho e farelo de soja, resultando em diferentes níveis de energia $(2,42 ; 2,66$; e 2,83 Mcal de energia metabolizável (EM)/kg de matéria seca (MS)). Uma mistura mineral foi acrescentada ao concentrado (Tabelas 1 e 2). A ração de maior nível de EM foi formulada para atender aos requerimentos de ganhos de peso diários médios de $300 \mathrm{~g} / \mathrm{animal} / \mathrm{dia}$, segundo o NRC (1985).

A duração do experimento foi definida pelo tempo necessário para que todos os animais, de cada tratamento, alcançassem peso médio de $33 \mathrm{~kg}$, quando os animais foram abatidos. Os animais foram pesados ao início do experimento, ao final do período de adaptação, compreendido em 28 dias, e a cada 14 dias durante o período experimental. Também ocorreram

Tabela 1 - Composição percentual dos ingredientes das dietas

Table 1 - Percentage of the ingredients of the diets

\begin{tabular}{|c|c|c|c|}
\hline $\begin{array}{l}\text { Ingredientes } \\
\text { Ingredients }\end{array}$ & \multicolumn{3}{|c|}{$\begin{array}{c}\text { Níveis de energia metabolizável } \\
\text { na dieta (Mcal/kg MS)* } \\
\text { Levels of metabolizable } \\
\text { energy of the diet (Mcal/kg DM) }\end{array}$} \\
\hline $\begin{array}{l}(\% \mathrm{MS}) \\
(\% \mathrm{DM})\end{array}$ & 2,42 & 2,66 & 2,83 \\
\hline $\begin{array}{l}\text { Milho } \\
\text { Corn }\end{array}$ & 14,15 & 35,08 & 56,41 \\
\hline $\begin{array}{l}\text { Farelo de soja } \\
\text { Soybean meal }\end{array}$ & 23,36 & 22,40 & 21,32 \\
\hline $\begin{array}{l}\text { Feno de tifton } \\
\text { Tifton hay }\end{array}$ & 61,70 & 41,43 & 20,86 \\
\hline $\begin{array}{l}\text { Calcário } \\
\text { Limestone }\end{array}$ & 0,30 & 0,60 & 0,91 \\
\hline $\begin{array}{l}\text { Sal mineral } \\
\text { Mineral salt }\end{array}$ & 0,49 & 0,49 & 0,50 \\
\hline
\end{tabular}

* Obtidos como valor médio de NDT das dietas de seis animais em cada tratamento (Alves, 2002).

* Obtained as average value of dietary TDN of six animals in each treatment (Alves, 2002). 
Tabela 2 - Teores de matéria seca (MS), proteína bruta (PB), extrato etéreo (EE), carboidratos totais (CHOT) carboidratos não fibrosos (CNF), fibra em detergente neutro (FDN), fibra em detergente ácido (FDA), matéria mineral (MM) matéria orgânica (MO) e nutrientes digestíveis totais (NDT) das dietas

Table 2 - Contents of dry matter (DM), cude protein (CP), ether extract (EE), total carbohydrates (TCHO), nonfiber carbohydrates (NFC), neutral detergent fiber (NDF) and acid (ADF), mineral matter (MM) and organic $(\mathrm{MO})$ and total digestible nutrients (TDN) of the diets

\begin{tabular}{|c|c|c|c|}
\hline \multirow[t]{2}{*}{$\begin{array}{l}\text { Nutrientes } \\
\text { Nutrients }\end{array}$} & \multicolumn{3}{|c|}{$\begin{array}{l}\text { Níveis de energia metabolizável } \\
\text { na dieta (Mcal/kg MS)* } \\
\text { Leves of metabolizable } \\
\text { energy of the diet (Mcal/kg DM) }\end{array}$} \\
\hline & 2,42 & 2,66 & 2,83 \\
\hline$\overline{\mathrm{MS}(\%)(D M)}$ & 87,57 & 87,36 & 87,16 \\
\hline $\mathrm{PB} * *(C P)$ & 18,48 & 18,51 & 18,48 \\
\hline $\operatorname{EE}^{* *}(E E)$ & 1,82 & 2,49 & 3,17 \\
\hline $\mathrm{CHOT}^{* *}($ TCHO $)$ & 73,02 & 73,15 & 73,33 \\
\hline $\mathrm{CNF}^{* *}(N F C)$ & 14,72 & 28,92 & 43,37 \\
\hline $\mathrm{FDN}^{* *}(N D F)$ & 58,30 & 44,23 & 29,96 \\
\hline $\mathrm{FDA}^{* *}(A D F)$ & 29,40 & 21,39 & 13,26 \\
\hline $\mathrm{MM}^{* *}(M M)$ & 6,68 & 5,85 & 5,01 \\
\hline $\mathrm{MO}^{* *}(O M)$ & 93,32 & 94,14 & 94,98 \\
\hline $\operatorname{NDT}(\%)(T D N)$ & 66,90 & 73,72 & 78,33 \\
\hline
\end{tabular}

* Obtidos como valor médio de NDT das dietas de seis animais em cada tratamento (Alves, 2002).

* Obtained as average value of dietary TDN of six animals in each treatment (Alves, 2002).

pesagens intermediárias, quando o $\mathrm{PV}$ dos animais se aproximou do peso determinado para abate. Antes do abate, os animais permaneceram em jejum de sólidos por 18 horas. Decorrido este tempo, foram novamente pesados para obtenção do peso vivo ao abate (PVA), objetivando determinação da perda de peso decorrente do jejum imposto $(\mathrm{PJ})$, que foi calculada da seguinte maneira: PJ $(\%)=($ PV - PVA $) \times 100 /$ PVA.

No momento do abate, os animais foram insensibilizados com descarga elétrica, seguida por sangria, através da seção das carótidas e jugulares, com conseqüente recolhimento do sangue em balde previamente tarado, para posteriores pesagem e identificação.

Após o abate, o conteúdo do trato gastrintestinal foi retirado para determinação do peso do corpo vazio (PCV), visando avaliar o rendimento biológico ou verdadeiro (RV) em que RV $(\%)$ = peso da carcaça quente (PCQ)/PCV X 100. Após a esfola, evisceração, retirada da cabeça, patas e órgãos genitais, foi obtido o PCQ.

Obtiveram-se também os pesos dos constituintes não-carcaça, que corresponderam aos órgãos (fígado, rins, aparelho respiratório, baço, língua e coração), que foram pesados, esvaziados e, juntamente com as vísceras (rúmen/retículo, omaso, abomaso, intestinodelgado e intestino grosso), lavados e pesados, separadamente.

Posteriormente, as carcaças foram resfriadas por 24 horas a $\pm 4^{\circ} \mathrm{C}$, e pesadas para obtenção do peso da carcaça fria (PCF). Na oportunidade, foi calculada a perda por resfriamento (PR), em que PR $(\%)=(\mathrm{PCQ}-\mathrm{PCF}) \times 100 / \mathrm{PCQ}$ e o rendimento comercial da carcaça ou rendimento da carcaça fria (RCF), que representa a relação entre o PCF e PVA, expresso em porcentagem.

Foram calculados os índices de compacidade da carcaça, obtidos por intermédio do PCF dividido pelo comprimento interno da carcaça (distância entre os pontos médios da borda cranial do púbis e a borda cranial da primeira costela) e compacidade da perna, por meio da relação entre a largura da garupa e o comprimento de perna (Reis et al., 2001). Posteriormente, a carcaça foi seccionada ao meio e, na meiacarcaça esquerda, foi efetuado um corte transversal, à altura da $13^{\mathrm{a}}$ costela, para mensuração do perímetro do músculo Longissimus dorsi, que foi obtido utilizando-se folhas de transparências. Em seguida, com um planímetro, foi determinada a área do referido músculo, denominada área do olho de lombo (AOL). Ainda, no Longissimus dorsi, utilizando-se paquímetro, foi mensurada a espessura de gordura de cobertura sobre sua secção, que foi obtida medindose o comprimento do referido músculo, partindo-se de um ponto zero, na sua porção anterior, para, em seguida, efetuar a mensuração da espessura de gordura de cobertura à altura de $2 / 3$ do comprimento (Oliveira, 1998).

A meia-carcaça esquerda foi subdividida em seis regiões anatômicas (cortes comerciais), as quais foram pesadas individualmente, determinando-se posteriormente as porcentagens que representavam em relação ao todo, com modificações das metodologias descritas por Colomer-Rocher (1988) e Medeiros (2001).

O pescoço constituiu a região compreendida entre a $1^{\mathrm{a}}$ a $7^{\mathrm{a}}$ vértebras cervicais; paleta foi a região que tem como base óssea a escápula, úmero, rádio, ulna e carpo; costela compreendeu a seção entre a $1^{\mathrm{a}}$ e $13^{\mathrm{a}}$ vértebras torácicas, que foi dividida ao meio com um corte transversal, subdividindo-a em costela superior e costela inferior, que incluiu o esterno; o lombo correspondeu à região das vértebras lombares; e a

R. Bras. Zootec., v.32, n.6, p.1927-1936, 2003 (Supl. 2) 
perna foi considerada a base óssea do tarso, tíbia, fêmur, ísquio, ílio, púbis, vértebras sacras e as duas primeiras vértebras coccígeas.

O delineamento experimental utilizado foi em blocos casualizados, com três tratamentos e seis repetições, fazendo-se a interpretação estatística dos resultados por meio de análises de variância e regressão. Os pesos dos animais foram controlados nos blocos.

Os critérios utilizados para escolha das equações foram o comportamento biológico, coeficiente de determinação $\left(\mathrm{r}^{2}\right)$, que foi calculado como a relação entre a soma de quadrado de regressão e a soma de quadrado total, e a significância, para os parâmetros da regressão, obtida pelo teste t, para os níveis de 1 e $5 \%$ de probabilidade.

\section{Resultados e Discussão}

Constam na Tabela 3 as médias, os coeficientes de variação $(\mathrm{CV})$, as equações de regressão e o coeficiente de determinação $\left(\mathrm{r}^{2}\right)$ das características de carcaça, em função dos níveis de energia das rações experimentais.
A influência do peso vivo (PV) sobre o rendimento da carcaça pode ser alterada pelo conteúdo gastrintestinal, o qual, por sua vez, é influenciado pelo número de horas em jejum a que os animais são submetidos e pelo tipo de dieta. Como pode ser observado, houve efeito linear decrescente para perda no jejum (PJ) e linear crescente para peso da carcaça quente (PCQ), rendimento da carcaça quente (RCQ), peso da carcaça fria (PCF), rendimento da carcaça fria (RCF) e peso do corpo vazio (PCV); enquanto a perda por resfriamento (PR) e o rendimento verdadeiro (RV) não foram influenciados pelos níveis de energia na dieta.

Em virtude de a relação volumoso:concentrado ter diminuído com o incremento da concentração energética da ração, como pode ser observado na Tabela 2, o comportamento observado para PJ, pode ser explicado pelo fato dos animais que receberam dietas com maior proporção de volumoso, portanto, alimento cujo tempo de retenção no rumem é maior, comparado aos que foram alimentados com dietas mais concentradas, terem, em termos percentuais,

Tabela 3 - Médias \pm erro-padrão, coeficiente de variação (CV), equações de regressão (ER) e coeficiente de determinação $\left(r^{2}\right)$ para perda ao jejum $(P J)$, peso da carcaça quente $(P C Q)$, rendimento da carcaça quente (RCQ), peso da carcaça fria (PCF), rendimento da carcaça fria (RCF), perda no resfriamento (PR), peso do corpo vazio (PCV) e rendimento verdadeiro (RV), em função dos níveis de energia metabolizável (EM) das dietas

Table 3 - Means \pm standard error, coefficient of variation (CV), regression equations (RE) and coefficient of determination ( $\left.r^{2}\right)$, for fasting loss (FL), hot carcass weight (HCW), hot carcass dressing (HCD), cold carcass weight (CCW), cold carcass dressing (CCD), cooling loss (LC), empty body weight (EBW) and true dressing (TD), in function of the metabolizable energy levels (ME) in the diets

\begin{tabular}{|c|c|c|c|c|c|c|}
\hline \multirow[t]{2}{*}{$\begin{array}{l}\text { Variáveis } \\
\text { Variables }\end{array}$} & \multicolumn{3}{|c|}{$\begin{array}{c}\text { Níveis de EM (Mcal/kg MS) } \\
\text { ME levels }(\text { Mcal/kg DM) }\end{array}$} & \multirow[t]{2}{*}{$\mathrm{CV}(\%)$} & \multirow[t]{2}{*}{$\mathrm{ER}(R E)$} & \multirow[t]{2}{*}{$\mathrm{r}^{2}$} \\
\hline & 2,42 & 2,66 & 2,83 & & & \\
\hline $\begin{array}{l}\mathrm{PJ}(\%) \\
F L\end{array}$ & $5,36 \pm 0,33$ & $2,46 \pm 0,42$ & $2,91 \pm 0,64$ & 18,68 & $\mathrm{Y}=18,30821-5,60245^{* *} \mathrm{EM}$ & 0,36 \\
\hline $\begin{array}{l}\mathrm{PCQ}(\mathrm{kg}) \\
\mathrm{HCW}\end{array}$ & $14,50 \pm 0,14$ & $16,57 \pm 0,29$ & $16,33 \pm 0,25$ & 5,39 & $\mathrm{Y}=4,33495+4,35916 * * \mathrm{EM}$ & 0,49 \\
\hline $\begin{array}{l}\mathrm{RCQ}(\%) \\
H C D\end{array}$ & $45,53 \pm 0,62$ & $50,08 \pm 1,12$ & $49,69 \pm 0,99$ & 5,37 & $\mathrm{Y}=20,35177+10,75942 * * \mathrm{EM}$ & 0,38 \\
\hline $\begin{array}{l}\mathrm{PCF}(\mathrm{kg}) \\
C C W\end{array}$ & $14,26 \pm 0,13$ & $16,30 \pm 0,25$ & $15,97 \pm 0,27$ & 5,28 & $\mathrm{Y}=4,33073+4,25562 * * \mathrm{EM}$ & 0,50 \\
\hline $\begin{array}{l}\mathrm{RCF}(\%) \\
C C D\end{array}$ & $44,80 \pm 0,59$ & $49,27 \pm 1,00$ & $48,57 \pm 1,03$ & 5,14 & $\mathrm{Y}=20,22453+10,40315 * * \mathrm{EM}$ & 0,40 \\
\hline $\begin{array}{l}\mathrm{PR}(\%) \\
L C\end{array}$ & $1,60 \pm 0,42$ & $1,59 \pm 0,38$ & $2,26 \pm 0,22$ & 53,13 & $\mathrm{Y}=1,82$ & \\
\hline $\begin{array}{l}\mathrm{PR}(\mathrm{kg}) \\
L C\end{array}$ & $0,23 \pm 0,06$ & $0,27 \pm 0,07$ & $0,37 \pm 0,03$ & 47,58 & $Y=0,29$ & \\
\hline $\begin{array}{l}\mathrm{PCV}(\mathrm{kg}) \\
E B W\end{array}$ & $27,30 \pm 0,68$ & $29,29 \pm 0,14$ & $29,15 \pm 0,28$ & 3,76 & $\mathrm{Y}=15,82465+4,81548 * * \mathrm{EM}$ & 0,43 \\
\hline $\begin{array}{l}\mathrm{RV}(\%) \\
T D\end{array}$ & $53,24 \pm 1,17$ & $56,55 \pm 0,92$ & $56,04 \pm 0,90$ & 5,07 & $Y=55,28$ & \\
\hline
\end{tabular}

* ${ }^{* *}$ Significativo a 5 e $1 \%$ de probabilidade, respectivamente pelo teste $\mathrm{T}$.

*, * Significant at 5 and $1 \%$ of probability, respectively, by $T$ test. 
maior quantidade de digesta a ser excretada. Então, considerando que todos os animais experimentais permaneceram em jejum sólido por 18 horas e foram abatidos com aproximadamente $33 \mathrm{~kg}$ de PV, pode-se constatar que nos tratamentos com maior proporção de feno, o esvaziamento do trato gastrintestinal (TGI) tenha sido mais lento, antes da mensuração do PV.

Quanto aos pesos e rendimentos de carcaças quente e fria, bem como o PCV, a resposta observada já era esperada, visto que o aumento da concentração energética da dieta ocasiona menor conteúdo gastrintestinal (ARC, 1980; Owens et al., 1993), que, por sua vez está diretamente relacionado com os parâmetros acima citados.

Esses comportamentos corroboram os obtidos por Mahgoub et al. (2000), trabalhando com 2,39; 2,47; e 2,74 Mcal de energia metabolizável (EM)/kg de matéria seca (MS) na dieta de ovinos Omani e, Martins et al. (1999), avaliando as características quantitativas da carcaça de cordeiros mestiços Texel, terminados em confinamento com diferentes níveis de energia. Contudo, Silva \& Pires (2000), trabalhando com 2,8 Mcal EM/kg de MS em dieta de ovinos mestiços Texel x Ideal, abatidos, em média, com $33 \mathrm{~kg}$, encontraram valores inferiores aos obtidos neste estudo, de $28,33 \mathrm{~kg} ; 14,01 \mathrm{~kg} ; 13,75 \mathrm{~kg} ; 42,84 \%$; $42,26 \%$; e $48,55 \%$ para PCV, PCQ, PCF, RCQ, RCF e RV, respectivamente. Também como Reis et al. (2001), quando avaliaram as características de carcaça de cordeiros alimentados com dietas contendo grãos de milho conservados em diferentes formas. Garcia et al. (1999), trabalhando com 2,6 Mcal de EM/kg de MS em ovinos Ideal x Ile de France abatidos aos $34 \mathrm{~kg}$, encontraram valores inferiores aos obtidos neste estudo, ao comparem dois níveis de EM (2,66 e 2,83 Mcal de EM/kg de MS), para PCV, PCQ, PCF e RCF.

Quanto aos rendimentos de carcaças, trabalhos demonstram existir grande variabilidade (45 a 60\%), em função de vários fatores, como genética, sexo, idade, peso vivo, peso ao nascer, número de horas em jejum e dieta imposta aos animais (Sañudo \& Sierra, citados por Siqueira \& Fernandes, 1999).

Em relação ao RV, não houve diferença significativa, podendo ser explicado devido o conteúdo gastrintestinal ter sido eliminado. Esse comportamento observado está de acordo com o relatado por Zundt et al. (2001), que não verificaram efeito significativo quando alimentaram caprinos com diferentes níveis de energia na dieta. Contudo, os valores obti- dos foram maiores que os encontrados por Garcia et al. (1999), quando comparados com os níveis de 2,66 e 2,83 Mcal de EM/kg de MS, mostrando o potencial da raça Santa Inês como produtora de carne.

As médias, coeficientes de variação (CV), equações de regressão e coeficientes de determinação $\left(\mathrm{r}^{2}\right)$, para os cortes, expressos em kg e em porcentagem do peso da carcaça fria; índice de compacidade da carcaça (ICC) em kg/ cm, índice de compacidade de perna (ICP), espessura de gordura (EG) em mm e área de olho de lombo (AOL), em cm² ${ }^{2}$ em função dos níveis de energia da dieta estão apresentados na Tabela 4. Observa-se que não houve efeito para nenhuma das variáveis analisadas, exceto para peso de paleta e costela superior, que mostraram efeito linear crescente com o incremento nos níveis de energia na dieta, embora, de modo geral, observou-se que os valores absolutos aumentaram com elevação da EM na dieta.

Observou-se que os cortes como perna e paleta foram os que apresentaram maiores rendimentos em relação ao peso da carcaça fria. Isso pode ser explicado pela maior quantidade de tecido muscular que esses cortes possuem, quando comparados com os demais.

De maneira geral, os valores obtidos neste trabalho estão próximos, em valores absolutos, aos encontrados por Siqueira et al. (2001), que trabalharam com cordeiros mestiços Ile de France x Corriedale, abatidos aos $33 \mathrm{~kg}$ de $\mathrm{PV}$, e inferiores para os cortes, paleta, lombo e pernil em relação aos valores encontrados por Pérez et al. (1998a), quando alimentaram ovinos Santa Inês com dietas contendo 2,7 Mcal EM/kg de MS. Quanto às percentagens de cortes em relação ao PCF, foram encontrados valores superiores aos obtidos por Garcia et al. (2001b), quando avaliaram dietas com 2,8 Mcal de EM/kg de MS, compostas por $80 \%$ de concentrado para ovinos Santa Inês, abatidos aos $35 \mathrm{~kg}$ de PVA.

Os índices de compacidade de carcaça (ICC) e perna (ICP) não foram influenciados pela inclusão de energia da dieta, corroborando com Martins et al (1999), quando trabalharam com 2,17 e 1,72 Mcal $\mathrm{EM} / \mathrm{kg}$ de MS. No entanto, os resultados encontrados neste trabalho, em todos os níveis de energia utilizados, foram superiores aos encontrados por esses autores, porém inferiores aos encontrados por Garcia et al. (1999), quando avaliaram dieta com 2,6 Mcal $\mathrm{EM} / \mathrm{kg}$ de MS em cordeiros inteiros Ideal x Ile de France. Por outro lado, Zundt et al. (2001), avaliando 
Tabela 4 - Médias \pm erro-padrão, coeficientes de variação (CV), equações de regressão (ER) e coeficiente de determinação $\left(r^{2}\right)$, para os cortes de paleta, perna, pescoço, costela superior (Cost. Sup.), costela inferior (Cost. Inf.) e lombo, e suas porcentagem em relação ao peso da carcaça fria (PCF), índice de compacidade da carcaça (ICC), índice de compacidade de perna (ICP), espessura de gordura (EG) e área de olho de lombo (AOL), em função dos níveis de energia metabolizável (EM) das dietas

Table 4 - Means \pm standard error, coefficients of variation (CV), regression equations (RE) and coefficient of determination $\left(r^{2}\right)$, for the cuts of shoulder, leg, neck, higher rib, less rib and loin, and its percentage in relation to the cold carcass weight $(C C W)$, carcass compactness index (CCl), leg compactness index (LCI), fat thickness (FT) and loin eye area (LEA), in function of the metabolizable energy levels (ME) of the diets

\begin{tabular}{|c|c|c|c|c|c|c|}
\hline \multirow[t]{2}{*}{$\begin{array}{l}\text { Variáveis } \\
\text { Variables }\end{array}$} & \multicolumn{3}{|c|}{$\begin{array}{c}\text { Níveis de EM (Mcal/kg MS) } \\
\text { ME levels (Mcal/kg DM) }\end{array}$} & \multirow[t]{2}{*}{$\mathrm{CV}(\%)$} & \multirow[t]{2}{*}{$\mathrm{ER}(R E)$} & \multirow[t]{2}{*}{$\mathrm{r}^{2}$} \\
\hline & 2,42 & 2,66 & 2,83 & & & \\
\hline $\begin{array}{l}\text { Paleta }(\mathrm{kg}) \\
\text { Shoulder }\end{array}$ & $1,29 \pm 0,02$ & $1,45 \pm 0,05$ & $1,46 \pm 0,04$ & 7,38 & $\mathrm{Y}=0,48070+0,34886 * \mathrm{EM}$ & 0,29 \\
\hline $\begin{array}{l}\text { Perna }(\mathrm{kg}) \\
\text { Leg }\end{array}$ & $2,32 \pm 0,07$ & $2,79 \pm 0,09$ & $2,62 \pm 0,11$ & 10,46 & $\mathrm{Y}=2,58$ & \\
\hline $\begin{array}{l}\text { Pescoço }(\mathrm{kg}) \\
\text { Neck }\end{array}$ & $0,75 \pm 0,04$ & $0,79 \pm 0,02$ & $0,86 \pm 0,05$ & 11,06 & $\mathrm{Y}=0,80$ & \\
\hline $\begin{array}{l}\text { Cost. Sup. }(\mathrm{kg}) \\
\text { Higher rib }(\mathrm{kg})\end{array}$ & $0,98 \pm 0,02$ & $1,12 \pm 0,03$ & $1,16 \pm 0,03$ & 6,77 & $\mathrm{Y}=0,08155+0,38144 * * \mathrm{EM}$ & 0,50 \\
\hline $\begin{array}{l}\text { Cost. Inf. (kg) } \\
\text { Less rib }\end{array}$ & $0,94 \pm 0,08$ & $1,02 \pm 0,03$ & $1,08 \pm 0,11$ & 17,11 & $\mathrm{Y}=1,01$ & \\
\hline $\begin{array}{l}\text { Lombo }(\mathrm{kg}) \\
\text { Loin }(k g)\end{array}$ & $0,83 \pm 0,02$ & $0,96 \pm 0,02$ & $0,84 \pm 0,05$ & 11,54 & $\mathrm{Y}=0,87$ & \\
\hline $\begin{array}{l}\text { Paleta (\%PCF) } \\
\text { Shoulder (\% WCC) }\end{array}$ & $18,06 \pm 0,25$ & $17,83 \pm 0,43$ & $18,32 \pm 0,58$ & 5,45 & $Y=18,07$ & \\
\hline $\begin{array}{l}\text { Perna }(\% \mathrm{PCF}) \\
\text { Leg }(\% W C C)\end{array}$ & $32,51 \pm 0,87$ & $34,14 \pm 0,69$ & $32,81 \pm 0,95$ & 6,84 & $Y=33,15$ & \\
\hline $\begin{array}{l}\text { Pescoço (\%PCF) } \\
\text { Neck }(\% W C C)\end{array}$ & $10,49 \pm 0,47$ & $9,77 \pm 0,35$ & $10,76 \pm 0,66$ & 12,98 & $\mathrm{Y}=10,34$ & \\
\hline $\begin{array}{l}\text { Cost. Sup (\%PCF) } \\
\text { Higher rib (\%WCC) }\end{array}$ & $13,78 \pm 0,26$ & $13,77 \pm 0,27$ & $14,50 \pm 0,24$ & 7,11 & $Y=14,02$ & \\
\hline $\begin{array}{l}\text { Cost. Inf. (\% } \% \text { PCF) } \\
\text { Less rib (\%WCC) }\end{array}$ & $13,19 \pm 1,12$ & $13,58 \pm 0,29$ & $13,49 \pm 1,38$ & 19,88 & $Y=13,09$ & \\
\hline $\begin{array}{l}\text { Lombo }(\% \mathrm{PCF}) \\
\text { Loin }(\% W C C)\end{array}$ & $11,60 \pm 0,33$ & $11,77 \pm 0,43$ & $10,51 \pm 0,53$ & 10,54 & $Y=11,29$ & \\
\hline
\end{tabular}

níveis de energia sobre os ICC e ICP em caprinos, observaram aumento linear crescente apenas para ICC.

Quanto à espessura de gordura de cobertura (EG) e área de olho de lombo (AOL), não foram encontrados efeitos significativos. O comportamento observado para AOL refletiu o mesmo verificado para ICC, o que já era esperado, visto que, ambas as variáveis expressam a musculosidade da carcaça.

Para a resposta dos constituintes não-carcaça em função dos níveis de energia das dietas experimentais (Tabela 5), não foi observado efeito significativo para todos os constituintes, exceto para GI e (CTGI e R/R), que mostraram efeito linear crescente e decrescente, respectivamente.

Os pesos do coração e aparelho respiratório não foram influenciados pelos níveis de energia na dieta, o que já era esperado, pois estes órgãos mantém sua integridade, por terem prioridades na utilização de nutrientes, independentemente da alimentação, de acordo com Perón et al. (1993), Ferreira et al. (2000) e Véras et al. (2001).

Em relação aos pesos do fígado, rins e baço não foi verificada resposta significativa, embora fosse esperado aumento linear, uma vez que esses órgãos, especialmente o fígado, têm altas taxas metabólicas, porque participam ativamente no metabolismo de nutrientes e, portanto, responde à sua ingestão de energia (Ferrell \& Jenkins, 1998, a, b; Owens et al., 1993).

Siqueira et al. (2001), trabalhando com cordeiros mestiços Ile de France e Corriedale, com 2,4 Mcal de $\mathrm{EM} / \mathrm{kg}$ de MS e abatidos aos $32 \mathrm{~kg}$, observaram menores valores para os componentes, fígado, baço e maiores para os componentes rins e coração. Contudo, Pérez et al. (1998, b), trabalhando com 2,7 Mcal EM/kg de MS em dietas de ovinos Santa Inês, encontraram valores superiores aos encontrados neste estudo. 
O crescimento do rúmen/retículo pode ser influenciado por vários fatores, dentre eles a dieta (Lucci, 1989; Van Soest, 1994). Neste trabalho, pode-se observar que à medida que aumentaram os níveis dietéticos de energia, houve uma redução nos teores de FDN e FDA das dietas (Tabela 2) e, nesse o comportamento teve relação direta com o desenvolvimento do rúmen/retículo. Os resultados encontrados neste estudo corroboram com os encontrados por McLeod \& Baldwin (2000).

O peso do omaso, abomaso, intestino delgado e intestino grosso, na forma que foram expressos, não foram influenciados pelos níveis de EM na dieta, embora possa ser observado que, em geral, os valores absolutos diminuíram com o incremento de energia dietética. Van Soest (1994) relatou que dietas com altos níveis de energia provocam involução do omaso. Esse comportamento está coerente com os encontra- dos por McLeod \& Baldwin (2000), quando trabalharam com os níveis de 2,29 e 2,81 Mcal de EM/kg de MS, para ovinos, e Véras et al. (2001).

A gordura é o componente que apresenta maior variação em função do nível nutricional. $\mathrm{O}$ aumento na quantidade de gordura interna, expresso pelo efeito linear crescente, comprova a habilidade fisiológica que esses animais possuem em depositar gordura intra-abdominal, devendo-se considerar, ainda, que toda a gordura do omento e mesentérica foi incorporada a esse componente. O resultado observado expressa os efeitos dos diferentes níveis de energia ingerida pelos animais que levaram ao aumento na deposição de gordura interna. A maior proporção de gordura interna acarreta, na prática, maiores exigências de energia para mantença, em razão da maior atividade metabólica do tecido adiposo. Considerando-se que a gordura interna não é apro-

Tabela 5 - Médias \pm erro-padrão, coeficientes de variação (CV), equações de regressão (ER) e coeficiente de determinação $\left(\mathrm{r}^{2}\right)$ dos constituintes não-carcaça, em kg, em função dos níveis de energia metabolizável (EM) das dietas

Table 5 - Means \pm standards error, coefficient of variation (CV), regression equation (RE) and coefficient of determination $\left(r^{2}\right)$ of the noncarcass constituents, in function of the metabolizable energy levels (ME) of the diets

\begin{tabular}{|c|c|c|c|c|c|c|}
\hline \multirow[t]{2}{*}{$\begin{array}{l}\text { Variáveis } \\
\text { Variables }\end{array}$} & \multicolumn{3}{|c|}{$\begin{array}{c}\text { Níveis de EM (Mcal/kg MS) } \\
\text { ME levels }(\text { Mcal/kg DM) }\end{array}$} & \multirow[t]{2}{*}{$\mathrm{CV}(\%)$} & \multirow[t]{2}{*}{$\mathrm{ER}(R E)$} & \multirow[t]{2}{*}{$\mathrm{r}^{2}$} \\
\hline & 2,42 & 2,66 & 2,83 & & & \\
\hline $\begin{array}{l}\text { Aparelho resp. } \\
\text { Respiratory organs }\end{array}$ & $0,53 \pm 0,02$ & $0,51 \pm 0,01$ & $0,54 \pm 0,04$ & 12,83 & $Y=0,52$ & \\
\hline $\begin{array}{l}\text { Coração } \\
\text { Heart }\end{array}$ & $0,16 \pm 0,01$ & $0,17 \pm 0,01$ & $0,17 \pm 0,01$ & 11,45 & $\mathrm{Y}=0,17$ & \\
\hline $\begin{array}{l}\text { Fígado } \\
\text { Liver }\end{array}$ & $0,57 \pm 0,02$ & $0,63 \pm 0,02$ & $0,67 \pm 0,03$ & 9,23 & $Y=0,62$ & \\
\hline $\begin{array}{l}\text { Rins } \\
\text { Kidney }\end{array}$ & $0,12 \pm 0,00$ & $0,12 \pm 0,00$ & $0,15 \pm 0,02$ & 18,50 & $\mathrm{Y}=0,13$ & \\
\hline $\begin{array}{l}\text { Baço } \\
\text { Spleen }\end{array}$ & $0,10 \pm 0,01$ & $0,09 \pm 0,00$ & $0,11 \pm 0,02$ & 28,71 & $\mathrm{Y}=0,10$ & \\
\hline $\begin{array}{l}\text { Rúmen/Retículo } \\
\text { Rumen/Reticulum }\end{array}$ & $0,80 \pm 0,03$ & $0,75 \pm 0,02$ & $0,69 \pm 0,03$ & 8,43 & $\mathrm{Y}=1,35330-0,23076 * * \mathrm{EM}$ & 0,33 \\
\hline $\begin{array}{l}\text { Omaso } \\
\text { Omasum }\end{array}$ & $0,09 \pm 0,00$ & $0,08 \pm 0,00$ & $0,07 \pm 0,00$ & 16,34 & $Y=0,08$ & \\
\hline $\begin{array}{l}\text { Abomaso } \\
\text { Abomasum }\end{array}$ & $0,12 \pm 0,01$ & $0,13 \pm 0,01$ & $0,13 \pm 0,01$ & 18,80 & $\mathrm{Y}=0,13$ & \\
\hline $\begin{array}{l}\text { Intestino delgado } \\
\text { Small intestine }\end{array}$ & $0,64 \pm 0,04$ & $0,60 \pm 0,03$ & $0,62 \pm 0,07$ & 16,64 & $Y=0,62$ & \\
\hline $\begin{array}{l}\text { Intestino grosso } \\
\text { Large intestine }\end{array}$ & $0,42 \pm 0,02$ & $0,46 \pm 0,03$ & $0,43 \pm 0,02$ & 12,21 & $Y=0,44$ & \\
\hline $\begin{array}{l}\text { Gordura interna } \\
\text { Internalfat }\end{array}$ & $0,62 \pm 0,05$ & $1,11 \pm 0,09$ & $1,13 \pm 0,20$ & 28,77 & $\mathrm{Y}=-3,08585+1,55546 * \mathrm{EM}$ & 0,53 \\
\hline $\begin{array}{l}\text { TGI }^{1} \\
D T\end{array}$ & $2,08 \pm 0,07$ & $2,02 \pm 0,08$ & $2,94 \pm 0,08$ & 8,98 & $Y=2,01$ & \\
\hline $\begin{array}{l}\mathrm{CTGI}^{2} \\
C D T\end{array}$ & $4,57 \pm 0,56$ & $3,81 \pm 0,21$ & $3,74 \pm 0,19$ & 20,33 & $\mathrm{Y}=10,46099-2,43332 * \mathrm{EM}$ & 0,24 \\
\hline
\end{tabular}

R. Bras. Zootec., v.32, n.6, p.1927-1936, 2003 (Supl. 2) 
veitada para consumo humano, há desperdício de energia alimentar (Ferreira et al., 2000).

O conteúdo do TGI diminuiu linearmente $(\mathrm{P}<0,05)$ com o aumento do nível de energia da dieta, o que pode ser explicado pela composição das dietas experimentais (Tabela 3). As rações com menores níveis de energia apresentaram maiores teores de fibra e menor digestibilidade, conforme Alves (2002), aumentando, dessa forma, o tempo de retenção do alimento no rúmen. Por outro lado, as rações com maiores níveis de energia apresentaram menores teores de fibra e maior digestibilidade, resultando em menor tempo de retenção (Alves, 2002). Esse resultado está de acordo com o ARC (1980) e Ferreira et al. (2000), os quais afirmam que a elevação da energia na ração, em consequiência da adição de concentrado, reduz o conteúdo do TGI.

\section{Conclusões}

Níveis crescentes de energia metabolizável na dieta de ovinos Santa Inês influenciam positivamente os peso da carcaça quente, rendimento de carcaça quente, peso da carcaça fria, rendimento de carcaça fria, peso do corpo vazio, corte da paleta, corte da perna e a quantidade de gordura interna e negativamente a perda no jejum, peso do rúmen/retículo e o conteúdo do trato gastrintestinal.

\section{Literatura Citada}

ALVES, K.S. Níveis de energia em dietas de ovinos Santa Inês: Digestibilidade aparente, desempenho, característica de carcaça e constituintes corporais. Recife: Universidade Federal Rural de Pernambuco, 2002. 80p. Dissertação (Mestrado em Zootecnia) - Universidade Federal Rural de Pernambuco, 2002.

AGRICULTURAL RESEARCH COUNCIL - ARC. The nutrient requirements of ruminats livestock. London: Commonwealth agricultural Bureaux, 1980.351p.

CARVALHO, S.R.S.T.; SIQUEIRA, E.R.. Produção de cordeiros em confinamento. In: SIMPÓSIO MINEIRO DE OVINOCULTURA: PRODUÇÃO DE CARNE NO CONTEXTO ATUAL, 1., 2001, Lavras. Anais...Lavras: Universidade Federal de Lavras, 2001. 125p.

COLOMER-ROCHER, F.C.; MORAND-FEHR, P.; KIRTON, A.H. et al. "Métodos normalizados para el estudio de los caracteres cuantitativos y cualitativos de las canales caprinas y ovinas". Cuadernos INIA, n.17, 1988. p.11-18.

GARCIA, C.A.; SILVA SOBRINHO, A.G.; GASTALDI, K.A. Influência das diferentes relações volumoso : concentrado e pesos de abate de cordeiros confinados. 1. Rendimento de cortes e característica das carcaça. In: REUNIÃO ANUAL DA SOCIEDADE BRASILEIRA DE ZOOTECNIA, 36., 1999, São Paulo. Anais... São Paulo: SBZ/Gmosis, [1999]
CD-ROM.Qualidade de produtos de origem animal. QUA018.

GARCIA, I.F.F.; PÉREZ, J.R.O.; OLIVEIRA, M.V. Característica de carcaça de cordeiros Texel x Bergamácia, Texel x Santa Inês puros, terminados em confinamento alimentados com casca de café como parte da dieta. Revista Brasileira de Zootecnia, v.29, n.1, p.564-572, 2000.

GARCIA, I.F.F.; PÉREZ, J.R.O.; BONARURIO, S. et al. Características de carcaça de cordeiros Santa Inês e cruzas Santa Inês com Texel, Ile de France e Bergamácia. In: REUNIÃO ANUAL DA SOCIEDADE BRASILEIRA DE ZOOTECNIA, 38., 2001, Piracicaba. Anais... Piracicaba: Sociedade Brasileira de Zootecnia, 2001a. p.1142.

GARCIA, I.F.F.; PÉREZ, J.R.O.; BONARURIO, S. et al. Percentagens de cortes na carcaça de cordeiros Santa Inês puros e cruzas com Texel, Ile de France e Bergamácia. In: REUNIÃO ANUAL DA SOCIEDADE BRASILEIRA DE ZOOTECNIA, 38., 2001, Piracicaba. Anais... Piracicaba: Sociedade Brasileira de Zootecnia, 2001b. p.1140.

FERREIRA, M.A.; VALADARES FILHO, S.C.; MUNIZ, E.B. et al. Características das carcaças, biometria do trato gastrintestinal, tamanho dos órgãos internos e conteúdo gastrintestinal de bovinos F1 Simental x Nelore alimentados com dietas contendo vários níveis de concentrado. Revista Brasileira de Zootecnia, v.29, n.4, p.1174-1182, 2000.

FERRELL, C.L.; JENKINS, T.G. Body composition and energy utilization by steers of diverse genotypes fed a highconcentrate diet during the finishing period: I. Angus, Belgian Blue, Hereford, and Piedmontese Sires. Journal of Animal Science, v.76, p.637-646, 1998a.

FERRELL, C.L.; JENKINS, T.G. Body composition and energy utilization by steers of diverse genotypes fed a high-conentrate diet during the finishing period: II. Angus, Boran, Brahman, Hereford, and Tuli Sires. Journal of Animal Science, v.76, p.647-657, 1998b.

KAMALZADEH, A.; KOOPS, W.J.; VAN BRUCHEM et al. Feed quality restriction and compensatory growth in growing sheep: development of body organs. Small Ruminant Research, v.29, n.1, p.71-82, 1998.

LUCCI, C.S. Bovinos leiteiros jovens. São Paulo: Nobel, 1989. $371 \mathrm{p}$.

MAHGOUB, O.; LU, C.D.; EARLY, R.J. Effects of dietary energy density on feed intake, body weight gain and carcass chemical composition of Omani growing lambs. Small Ruminant Research, v.37, n.1, p.35-42, 2000.

MARTINS, E.N.; MACEDO, F.A.F.; MACEDO, R.M.G. et al. Desempenho e características quantitativas da carcaça de cordeiros mestiços Texel, terminados em confinamento, com diferentes níveis de energia. In: REUNIÃO ANUAL DA SOCIEDADE BRASILEIRA DE ZOOTECNIA, 36, 1999, Porto Alegre. São Anais... Paulo: SBZ/Gmosis, [1999] CDROM.Qualidade de produtos de origem animal. QUA-034.

MCLEOD, K.R.; BALDWIN, R.L. Effects of diet forage : concentrate ratio and metabolizable energy intake on visceral organ growth and in vitro oxidative capacity of gut tissues in sheep. Journal of Animal Science, v.78, p.760-770, 2000.

MEDEIROS, A.N. Estimativa da composição corporal e exigências em proteína e energia para caprinos Saanen na fase inicial de crescimento. Jaboticabal: Universidade Estadual Paulista, 2001. 106p. Tese (Doutorado em Zootecnia) - Universidade Estadual Paulista, 2001.

NATIONAL RESEARCH COUNCIL - NRC. Nutrient requirements of sheep. 6.ed. Washington, D.C.: National 
Academy Press, 1985. 99p.

OLIVEIRA, E.R.; ANDRADE, I.F.; PAIVA, P.C.A. et al. Cama de frango formada com "casca de café" na engorda de novilhos confinados. In: REUNIÃO ANUAL DA SOCIEDADE BRASILEIRA DE ZOOTECNIA, 35., 1998, Botucatu. Anais... Botucatu: Sociedade Brasileira de Zootecnia, 1998a. p. 401 .

OLIVEIRA, S.R. Desempenho e característica da carcaça de novilhos Nelores não castrados. Viçosa, MG: Universidade Federal de Viçosa, 1998. 58p. Dissertação (Mestrado em Zootecnia) - Universidade Federal de Viçosa, 1998.

OLIVEIRA, S.R.; COELHO DA SILVA, J.F.; VALADARES FILHO, S.C. et al. Rendimento de carcaça e cortes básicos de novilhos Nelore recebendo rações com diferentes níveis de concentrado. In: REUNIÃO ANUAL DA SOCIEDADE BRASILEIRA DE ZOOTECNIA, 35., 1998, Botucatu. Anais... Botucatu: Sociedade Brasileira de Zootecnia, 1998b. p. 164

OSÓRIO, J.C.S. Estúdio de la calidad de canales comercializadas em el tipo ternasco segun la procedência: bases para la mejora de dicha calidad em Brasil. Zaragoza: Universidade de Zaragoza, Facultad de Veterinária, 1992.335p. Tese (Doutorado em Veterinária) - Universidade de Zaragoza, Facultad de Veterinária, 1992.

OSÓRIO, J.C.S.; OSÓRIO, M.T.; JARDIM, P.O. et al. Métodos para avaliação da produção da carne ovina: in vivo, na carcaça e na carne. Pelotas: Universidade Federal de Pelotas, 1998. $107 \mathrm{p}$.

OSÓRIO, J.C.S.; OSÓRIO, M.T.M. Sistemas de avaliação de carcaça no Brasil. In: SIMPÓSIO MINEIRO DE OVINOCULTURA: PRODUÇÃO DE CARNE NO CONTEXTO ATUAL, 1., 2001, Lavras. Anais...Lavras: Universidade Federal de Lavras, 2001. 198p.

OWENS, F. N.; DUBESKI, P.; HANSON, C.F. Factors that alter the growth and development of ruminants. Journal of Animal Science, v.71, p.3152-3172, 1993.

PÉREZ, J.R.O.; GARCIA, I.F.F.; TEIXEIRA, J.C. et al. Características de carcaça de cordeiros Santa Inês e Bergamácia com diferentes níveis de dejetos de suínos na dieta. In: REUNIÃO ANUAL DA SOCIEDADE BRASILEIRA DE ZOOTECNIA, 35., 1998, Botucatu. Anais... Botucatu: Sociedade Brasileira de Zootecnia, 1998a. p.176.

PÉREZ, J.R.O.; GARCIA, I.F.F.; TEIXEIRA, J.C. et al. Componentes corporais de cordeiros Santa Inês e Bergamácia com diferentes níveis de dejetos de suínos na dieta. In: REUNIÃO ANUAL DA SOCIEDADE BRASILEIRA DE ZOOTECNIA, 35., 1998, Botucatu. Anais... Botucatu: Sociedade Brasileira de Zootecnia, 1998b. p.179.
PERON, A.J.; FONTES, C.A.A.; LANA, R.P. et al. Tamanho dos órgãos internos e distribuição da gordura corporal em novilhos de cinco grupos genéticos, submetidos à alimentação restrita e ad libitum. Revista da Sociedade Brasileira de Zootecnia, v.22, n.5, p.813-819, 1993.

REIS, W.; JOBIM, C.C.; MACEDO, F.A.F. et al. Características da carcaça de cordeiros alimentados com dietas contendo grãos de milho conservados em diferentes formas. Revista Brasileira de Zootecnia, v.30, n.4, p.1308-1315, 2001.

SILVA , L.F.; PIRES, C.C. Avaliação quantitativa e predição das proporções de osso, músculo e gordura da carcaça em ovinos. Revista Brasileira de Zootecnia, v.29, n.4, p.1253-1260, 2000.

SILVA SOBRINHO, A.G.; SILVA, A.M.A. Produção de carne ovina - Parte II. Artigo técnico. Revista Nacional da Carne, N.286. Ano XXV, 2000. p-30-36.

SIQUEIRA, E.R.; FERNANDES, S. Peso, rendimentos e perdas da carcaça de cordeiros Corriedale e mestiços Ile de France X Corriedale, terminados em confinamento. Ciência Rural, v.29, n.1, p. 143-148, 1999.

SIQUEIRA, E.R.; SIMÕES, C.D.; FERNANDES, S. Efeito do sexo e do peso ao abate sobre a produção de carne de cordeiro. Morfometria da carcaça, pesos dos cortes, composição tecidual e componentes não constituintes da carcaça. Revista Brasileira de Zootecnia, v.30, n.4, p.1299-1307, 2001.

VÉRAS, A.S.C.; VALADARES FILHO, S.C.; SILVA, J.F.C. et al. Efeito do nível de concentrado sobre o peso dos órgãos internos e do conteúdo gastrintestinal de bovinos nelore não - castrado. In: REUNIÃO ANUAL DA SOCIEDADE BRASILEIRA DE ZOOTECNIA, 38., 2001, Piracicaba. Anais... Piracicaba: Sociedade Brasileira de Zootecnia, 2001. p.1130.

Van SOEST, P.J. Nutritional ecology of the ruminant. Ithaca: Comstock Publ. Association, 1994. 476p.

ZUNDT, M.; MACEDO, F.A.F.; ALCADE, C.R. et al. Características de carcaça de caprinos alimentados com diferentes níveis energéticos In: REUNIÃO ANUAL DA SOCIEDADE BRASILEIRA DE ZOOTECNIA, 38., 2001, Piracicaba. Anais... Piracicaba: Sociedade Brasileira de Zootecnia, 2001. p.992. 